\title{
EÇA, HUYSMANS \& SCHOPENHAUER: UMA IRONIA DA “DECADÊNCIA”
}

Onofre de Freitas*

RESUMO :

Sob o prisma da ironia humoresque, lê-se A correspondência de Fradique Mendes, de Eça de Queirós, no seu desdobramento intertextual. Preservando sempre a percepção dos efeitos da magia irônica, assinala-se a sua natureza textual de romanceensaio em que o literário, o científico e o filosófico se interseccionam, em permanente dialogismo. A partir deste pressuposto, busca-se, ainda através da ótica irônica, (des)tecer a malha intertextual, em perspectiva interna $e$ externa. Vale dizer: a sua intertextual ização é vista dentro da obra, através do dialogismo de suas partes entre si narrativa introdutória e epistolário (intertextualidade endógena); e ainda fora da obra, através do seu dialogismo com À rebours, de J.-K. Huysmans, e 0 mundo como idéia e representação, de Arthur Schopenhauer (intertextuaidade exógena).

PALAVRAS-CHAVE: ironia, intertextualidade, romance-ensaio.

Esta tese é desenvolvida em três partes que se articulam como as proposições de um silogismo. Inicia-se pela discussão do gênero de $A$ correspondência de Fradique Mendes, cujo caráter inovador prenuncia ruptura. Em seguida, analisase a estrutura desta obra de Eça, salientando-se alguns aspectos da sua (des) construção narrativa, e termina-se pelo estudo comparativo de $A$ correspondência de Fradique Mendes e À rebours, de J.-K. Huysmans, assinalando-se o (des)encontro intertextual dos dois autores, em Schopenllauer.

A correspondência de Fradique Mendes compõe-se de duas partes distintas: uma narrativa e outra epistolar. A primeira parte, à guisa de "Notas e Memórias", faz a apresentação biográfica de um suposto intelectual português C Fradique * Doutor em Letras: Estudos Literários (Área de concentração: Literatura Comparada), 2000. 


\section{EM TESE}

Belo Horizonte, v. 5, p. I-305, dez. 2002

Mendes. Um narrador, que se presume ser Eça de Queirós, conta como, quando e onde conheceu "esse homem admirável", com quem partilhou momentos de intimidade e por quem nutria a mais viva admiração. Mal se inicia o texto, atém-se o narrador à apreciação das LAPIDÁRIAS - cerca de cinco ou seis poesias, reunidas em folhetim, e sob esse título publicadas na Revolução de Setembro como da autoria de Fradique. Segue-se um minucioso e completo relato sobre as LAPIDÁRIAS, com a introdução de duas personagens de apoio: J. Teixeira de Azevedo (Jaime Batalha Reis) e Marcos Vidigal, este, personagem ficcional, aquele, amigo e camarada de Eça desde a época do Cenáculo (1867). A essa altura do texto, sai de cena o narrador em primeira pessoa e entra outro narrador, agora em terceira pessoa onisciente, para contar a vida pregressa de Fradique. É com apoio no testemunho daquele último (Marcos Vidigal, que se confessa parente, patrício e parceiro de Fradique) que o narrador recompõe 0 passado do seu biografado. Finda a narrativa retrospectiva, é retomada em primeira pessoa a narrativa progressiva, dentro de um novo estatuto de narração em que se misturam os discursos indireto, direto e indireto livre, e assim até o final da primeira parte.

A segunda parte consta do epistolário atribuído a Fradique, o qual se correspondia com vărios amigos e eminentes intelectuais da época. Entre estes, pessoas leais (como Antero de Quental, 01iveira Martins, etc.) e personagens fictícias. Como ensaiado na primeira parte, realidade e fantasia se alternam e misturam, figurando o jogo entre o real e o irreal, jogo esse contido, pois, também na pretensa Correspondência.

São 16 cartas ao todo, coligidas sem qualquer critério aparente, com indicação apenas do lugar de procedência e do mês ("Londres, maio", "Paris, dezembro"; etc.). Constituem "um conjunto de crônicas em forma epistolar", na apreciação de Antônio J. Saraiva. ${ }^{1}$ Estas "cartas-crônicas" trazem o repertório das opiniões queirosianas acerca de arte, literatura, política, filosofia e religião. A propósito, afirma Feliciano Ramos que "na criação de $A$ correspondência de Fradique Mendes, manifesta-se, não o paisagista ou crítico social, mas sim principalmente o 'ensaísta' com seu riquíssimo ideário". ${ }^{2}$

Efetivamente, nenhuma das cartas, nem mesmo as mais breves e despretensiosas (como a primeira, dirigida "Ao Visconde de A.-T", recomendando-1he 
o alfaiate Tomaz Cook) deixa de servir ao interesse maior de expressar uma opinião ou um gosto estético. No jogo que se estabelece entre a primeira e a segunda parte da obra, o leitor acaba por descobrir que o fingimento biográfico e o epistolar servem menos à fantasia do que à oportunidade de um debate sobre os diferentes temas aí versados. Entre estes, com destaque, o da criação literária.

Pela amostragem até aqui, pode-se verificar que o jogo ideológico se reflete na escrita, e deduz-se que Eça revela consciência do processo de construção desta sua obra, ao mesmo tempo que trabalha a linguagem com percepção de sua fragilidade como estabelecedora de sentido. A intenção metaliterária subjaz sob os aspectos meramente lúdicos, através dos quais Eça simula biografar "um grande homem"), documentando suas "Notas e Memórias" com depoimentos de amigos e uma coletânea de cartas atribuídas à excêntrica personagem biografada. Em conseqüência, A correspondência de Fradique Mendes se insere no conjunto daquelas obras em que Eça inscreve o legado de seu "testamento literário".3

Do exposto se deduz que $A$ correspondência de Fradique Mendes não pode ser lida sem a percepção da malha irônica de que se entretecem as suas duas partes. 0 próprio título já é irônico, tendo Eça hesitado entre (primeiro título) e Correspondência (título definitivo). ${ }^{4}$ Inicia-se, desse modo, a partir do título, a colocação do estatuto da palavra reversível e a perplexidade semântica como um pacto de jogo irônico.

A primeira parte contém várias incongruências (por ex.: o parentesco com Vidigal, o problema alfandegário com a múmia, etc.) que induzem o leitor à ironia, fazendo pensar que o autor não está falando sério, mas simulando um teatro de enganos. Além do mais, um intróito biográfico que já de início se põe a falar digressivamente de literatura (e as digressões literárias se repetem de tempo em tempo interferindo no andamento da narração) presta-se a informar o leitor de que Eça tenciona falar é de literatura, ou também de literatura. Em verdade o apresentador de Fradique simula biografar quando de fato intenta teorizar, e não apenas sobre arte, porém ainda sobre filosofia, política e religião.

0 leitor mais atento, ou antes, interessado na problemática poética, com pouco percebe que o autor não só teoriza mas faz experimento, transformando sua 


\section{EM TESE}

Belo Horizonte, v. 5, p. I-305, dez. 2002

narração em texto que se auto-exemplifica. Daí termos selecionado esse filete da metalinguagem de Eça para campo de nosso estudo e descobertas comparativas.

Ao aferir os processos construtivos do texto de $A$ correspondência de Fradique Mendes à luz das teorias e tendências finisseculares, acabamos por perceber analogias e contrastes dignos de nota entre esta obra de Eça e $A$ rebours, de J.-K. Huysmans, principalmente quanto à sua arquitetura enunciativa e temática. Justificouse, assim, um paralelo entre ambos.

A correspondência de Fradique Mendes encerra um projeto metaliterário de singular importância para o entendimento do fenômeno da produção de textos e, mais significativo ainda, para a recepção da obra queirosiana, sobretudo a partir de Os Maias. As colocações e alusões contidas na primeira parte (à guisa de "Memórias e Notas") mais a teorização literária, explícita e implícita nas Cartas de Fradique, produzidas já na maturidade de Eça, representam (permitimo-nos supor) uma sintese expositiva e crítica das teorias vigentes, questionadas ou nascentes, a partir da segunda metade do Século XIX. Analisar A correspondência de Fradique Mendes acabou sendo, pois, um oportuno refletir sobre a arte literária no geral e, especificamente, um (re)pensá-la quanto à intrincada questão da construção narrativa.

Resumamos a seguir, parte por parte, as conclusões a que chegamos.

\section{PRIMEIRA PARTE: A CORRESPONDÊNCIA DE FRADIQUE MENDES - UMA CLASSIFICAÇÃO (IM)POSSÍVEL}

Após analisar os aspectos gerais e específicos, com apoio na opinião da maioria dos críticos, tendemos para reconhecer que $A$ correspondência de Fradique Mendes (1888) se enquadra na espécie romance-ensaio, uma modalidade literária que começava a se tornar moda nos fins do Século XIV. A história literária nos informa que, nos últimos 25 anos do Século XIV, predominava certa tendência para mesclar as séries literária e científica, em textos de conteúdo ora filosófico, ora científico. Nestes textos híbridos, o tom literário da linguagem sugeria o terreno ambíguo da 
arte e do conhecimento científico e filosófico. Como exemplo, citam-se as experiências de Oscar Wilde e, primordialmente, as de Huysmans, autor do romance À rebours, primeira obra nesta nova linha, dentro da literatura francesa. Pouco enredo, ou episódios desconexos, servindo de pretexto para debate de problemas sociais, políticos e filosóficos, com realce para a discussão do problema da arte - assim se pode definir o romance-ensaio ou romance científico. Esta nova modalidade narrativodissertativa tem como característica principal a sua preocupação com o metaliterário. Atendendo, pois, a este aspecto, A correspondência de Fradique Mendes discute, entre outros, o problema da arte, ocasião em que analisa não apenas a natureza da literatura, mas ainda a questão da produção e recepção de textos. Verificando-se mais, e ainda, que nesta obra Eça suscita principalmente a questão narrativa romanesca, na sua natureza híbrida de diegese/mimese (Platão, 1983) - pois constrói um jogo intertextual entre a narração introdutória e as cartas, fazendo nascer um valor romanesco do conjunto - propomos seja A correspondência de Fradique Mendes apreciada não apenas como um romance-ensaio mas, conseqüentemente, como um meta-romance.

Ao verificar os pontos doutrinais expostos por Eça sobre a arte literária, notamos que $A$ correspondência de Fradique Mendes, através de sua estrutura inovadora como romance (relaciona entre si textos desconexos: uma introdução fictícia e várias cartas), parece espelhar aquilo que doutrina. Ou seja: pode-se ver em $A$ correspondência de Fradique Mendes um elevado índice de auto-referencialidade. Sendo assim, cumpre reconhecer que Eça de Queirós, coerente com suas idéias afiliadas com o espírito vanguardista de seu tempo, demonstra, em A correspondência de Fradique Mendes, uma postura que se empenha na busca do 'novo' e já revela - como sugere Isabel Pires de Lima. ${ }^{5}$

\section{SEGUNDA PARTE: A (DES)CONSTRUÇÃO IRÔNICA}

A estrutura, de $A$ correspondência de Fradique Mendes coloca em dialogismo as duas partes de que se compõe: a introdução fictícia está em relação intextextual com as Cartas de Fradique. Chamemos a isso de autotextualidade (Genette/Dallenbach, 


\section{EM TESE}

Belo Horizonte, v. 5, p. I-305, dez. 2002

1979). ${ }^{6}$ Além disso, cada parte, através de citação, alusão, paráfrase ou paródia, remete a outro(s) texto(s) da tradição cultural, principalmente filosófica e literária, com o(s) qu(a1) (ais) mantém interlocução. Chamemos a esta relação de intertextualidade geral (Genette/Dallenbach, 1979).

Sendo assim, convenhamos, A correspondência de Fradique Mendes está estruturada para ser lida com ampla flexibilidade, segundo as relações dialógicas potenciais, ou antes, virtuais. A participação do leitor torna-se necessária e decisiva, tendo o autor abandonado a sua condição histórica de dono do discurso. 0 que permite esta abertura e enriquecimento do texto é, conforme observamos, a intertextualidade atuando como fator preponderante de sentido(s). A intertextualidade pode ser vista como um correlato dos efeitos da ironia e, como esta, também se al imenta da ambigüidade da linguagem, refletindo o ser e o parecer da realidade textual.

No caso de $A$ correspondência de Fradique Mendes, esta ambigüidade de ser/não ser um romance é que the dá o caráter de texto irônico que se forma de textos desconexos para serem lidos, ou não, como um conjunto. Daí entendermos que $A$ correspondência de Fradique Mendes possui uma estrutura (des)construída, o mesmo que dizer irônica. A intertextualidade interna das partes uma com a outra pode ser lida pelo caráter de complementaridade da introdução fictícia com as Cartas. Quanto à intertextualidade subinterna, cabe considerar que o texto introdutório começa numa linha memorialista, mas logo esta é desviada para a recensão cultural da época realista, com destaque para as idéias e a atuação literária do Grupo do Cenáculo, de que fez parte o seu autor e a personagem biografada. Ora volta ao histórico, ora diverge para o metaliterário e resvala no anedótico, misturando, assim, vários discursos. Quando trata da arte, o autor da introdução discute o problema da forma, concluindo que o real é indizível. Citando Fradique, que vive à procura da "tal prosa como não há", sugere que, ante a impossibilidade de alcançá-la, a opção é "trabalhar a linguagem", o que estamos em entender como exploração dos estratos ou veios irônicos da linguagem.

Ainda sob o aspecto da intertexlualidade subinterna, falando agora das Cartas, acabamos por perceber que estas guardam relações entre si, podendo ser lidas como vozes em dueto, terceto e até quinteto. Dentro desta possibilidade, lemos as 
cinco Cartas a/sobre Clara, dando-lhes o valor de um conto de amor narrado em capítulos. Várias alusões e apropriações feitas pelo autor destas Cartas podem nos conduzir a ver que, nelas, Fradique realiza uma (re)leitura do Trovadorismo, para discutir a questão da metafisíca do amor.

A propósito da intertextualidade geral, ou externa, descobrimos como mais evidentes, pelo menos para nós, as interlocuções de Eça com J.-K. Huysmans e Schopenhauer. Este ponto, culminante de nossa leitura, decidimos tratá-10 em separado, e constitui a terceira parte.

\section{TERCEIRA PARTE- EÇA E HUYSMANS: O (DES)ENCONTRO EM SCHOPENHAUER}

Eça e Huysmans pertencem à Geração Real ista. Ambos praticaram o Natural ismo como discípulos fiéis de Zola. Abandonaram, porém, o mestre antes da virada do século, tornando-se simpatizantes do Simbolismo. Quando esta guinada acontenceu, os meios literários viviam o auge do Decadentismo, sob a influência inovadora de Baudelaire e Rimbaud. Era, pois, natural que, a partir de então, viessem a criar as suas personagens pelo figurino dândi, moda condizente com aquele período de transição e reação contra o Naturalismo repetitivo e dogmático. Assim, tanto Fradique como Des Esseintes foram delineados pelo novo modelo, sendo conseqüentes as suas semelhanças, apesar das diferenças devidas à individualidade de cada autor. Daí a validade de têm paralelo entre $A$ correspondência de Fradique Mendes e $\bar{A}$ rebours, obras contemporâneas uma da outra, cujos heróis podem ser lidos como representativos do dandismo decadentista. Personagens típicas do final do século, Fradique e Des Esseintes amam o luxo e as excentricidades; usufruem o status de play-boys internacionais, buscando os prazeres mais raros e requintados proporcionados pela tecnologia, o que thes era garantido pela herança acumulada, herdada dos avós. A vida esvaída entre as vaidades

e os caprichos de pessoas ociosas, aventuras sentimentais, passatempos sociais e viagens de turismo pelo mundo não lhes tiram, entretanto, o gosto pelas leituras com que acumulam uma vasta cultura, produto desses "vinte séculos de literatura". Tanto 


\section{EM TESE}

Belo Horizonte, v. 5, p. I-305, dez. 2002

um como o outro tem o seu lado mundano, sem deixar ele ser um típico intelectual decadentista. Mas... viagens, amores, conforto e abastança acabam por exaurir as suas almas, tornando-as amargas, inquietas e infelizes ante o (en)fado de viver mergulhadas no spleen baudelairiano. Lêem na Imitação de Cristo: "Difficilis in otio quies".7 Ao pensarem sobre esta máxima, convencem-se de que, efetivamente, as suas vidas eram vazias... e decidem procurar um antídoto para o tédio. A interpretação da hora como final de mais uma etapa da história (donde nasce o Decadentismo) instaura, no fim do século XIX, o pessimismo e certa tendência para o místico, 0 esotérico e o satânico. A civilização que se supõe decadente fechava o ciclo tecnológico (a era dos paraísos artificiais), ao qual se pensava devesse suceder a vigência da lei natural. Uma volta ao passado, à tradição? Verifica-se o choque entre Natureza e Cultura, entre Fé e Ciência - dilemas de ordem ética e filosófica - de que se ocupam os homens finisseculares.

Ora, houve no princípio do século XIX um filósofo canhestro, um gauche, marginal e contestador, que andou pregando mais ou menos tais idéias, subvertendo o primado da Razão, que ele colocava subalterna à Intuição. Como é óbvio, foi considerado um louco e posto no esquecimento. Agora, porém, despertava do seu ostracismo para a glória e teria o seu nome consagrado pela Geração Decadentista, que descobria nele o Mestre para redimir a humanidade da sua angústia esplínica. Místico sem ser santo, gnóstico sem ser fanático, esse profeta do caos tecnológico dava ao mundo a solução para os seus problemas: voltar ao seio da Natureza e reger os seus impulsos selvagens pelo domínio da Vontade, ou seja: a autodisciplina. Esta a doutrina daquele que se tornou o filósofo do Decadentismo. 0 seu nome: Arthur Schopenhauer (1788-1862).

A explicação que Schopenhauer dava para o sofrimento estava no despotismo da Vontade que ele, ao identificá-la com a coisa-em-si, definia como "uma simples tendência, cega e irresistível, a qual encontramos tanto na natureza do reino inorgânico, como também na parte vegetativa da nossa vida" "Viver é Sofrer", conclui o Filósofo do Pessimismo, porque a Vontade nunca se satisfaz e, por trás de todo querer, haverá sempre outro desejo, e outro e outro mais ...

o Voluntarismo Schopenhaueriano é fundado numa certa, compreensão da alma humana e oferece ainda, para reforço de sua validade, argumentos bíblicos 
buscados ao Eclesiástico e ao Livro de Jó, e tem bastante afinidade com o Budismo. Sob o ponto de vista da sua ética, Schopenhauer acabava propondo um sincretismo de Budismo e Cristianismo, sintetizando o seu catecismo no "amor ao próximo". Prescrevia três caminhos para se atingir a felicidade, ou o "estado ético", o Nirvana: - a Prática da Arte, a Vida Contemplativa, o Trabalho Social. Tais são os meios, segundo ele, eficazes para o domínio da Vontade, os únicos ao alcance do homem.

Para a Geração Decadentista, frente às expectativas místicas e às profecias escatológicas para o final do Segundo Milênio, as idéias de Schopenhauer repercutiam como revelações valiosas. Isso explica a sua influência no final do Século XIX, e explica também como e por que, a partir de então até hoje, existe no mundo ocidental uma tendência para conhecimento e absorção da cultura oriental, especialmente a budista, o que se há de reconhecer como uma herança, schopenhaueriana.

Engajados neste contexto, Eça e Huysmans percorrem vários caminhos em busca da explicação para a angústia de seus heróis dândicos. Vão passando por vários filósofos, moralistas, teólogos, místicos, santos e poetas, até estacionarem em Schopenhauer, cuja doutrina lêem, discutem, experimentam, e finalmente rejeitam. Fradique e Des Esseintes são estruturados de modo a se parecerem com o ideal humano de Schopenhauer, transformando-se em experiências ficcionais de sua doutrinação ética. Nesse sentido, a experiência de Huysmans foi "Ās Avessas", porque Huysmans se converteu ao Catolicismo. A experiência de Eça ... bem! Eça não chegou a nenhuma solução radical. A sua personagem Fradique fará parte de uma galeria de heróis (Jacinto, Gonçalo, etc.) em cujo simbolismo se tem procurado ver a expressão máxima da ironia eciana, o seu instante de trégua com o radicalismo político, social, filosófico e estético, ou - como se pode concluir na esteira de Antônio Sérgio (Sérgio, 1980), Frank F. Sousa (Sousa, 1993), Paulo F. M. 01 iveira (01iveira, 1997), e outros - Eça parece ter vivido "um momento de equilíbrio e apaziguamento", ao construir "uma grande alegoria em que, ao menos ficcionalmente, uma terceira via é configurada, em que o país, para se manter enquanto tal, consegue e precisa seletivamente progredir". ${ }^{8}$ 


\section{EM TESE}

Belo Horizonte, v. 5, p. I-305, dez. 2002

NOTAS

1. História ilustrada das grandes literaturas, p. 245.

2. História da literatura portuguesa, p. 698

3. SIMÕES, João Gaspar. Eça de Queirós: a obra e o homem. Lisboa: Arcádia, [s.d.]. p. 183.

4. Idem, Ibidem.

5. 0 dandismo de Fradique ou o exercício impossível de um heroísmo decadente. In: Eça e Os Maias. Porto: ASA, 1990. p. 101-109.

6. Intertexto e autotexto. In: Poétique - intertextualidades, p. 51-76.

7. Difícil no ócio a paz.

8. OLIVEIRA, Paulo F. da Motta. Tradição e modernidade em A cidade e as serras. Boletim do CESP, v. 17, n. 21, p. 169, jan./dez. 1997.

RÉSUMÉ:

Dans cette thèse, on lit, sous le prisme de l'ironie humoresque, l'oeuvre A correspondência de Fradique Mendes, par Eça de Queirós, dans son développement intertextuel. En préservant toujours la perception des effects de la magie ironique, on signale sa nature textuelle de romanessay dans lequel le littéraire, le scientifique et le philosofique s'entrecroisent en permanent dialogisme. $\grave{A}$ partir de cete présupposition, on cherche, à travers l'optique ironique, (dé)tisser la maille intertextuelle, au point de vue interne et externe. Il vaut dire: l'intertextualité est vue au-dedans de l'eouvre, à travers le dialogisme de ses parts, entre elles-mêmes - narrative introductive et épistolographie (intertextualité endogénique); et encore au-dehors, à travers son dialogisme avec À retours, de J.-K. Huysmans, et avec Le monde comme volonté et répresentation, de Arthur Schopenhauer (intertextualité exogénique).

MOTS-CLÉS: ironie, intertextualité, roman-essai. 
QUEIRÓS, Eça de. Obra completa. Eça de Queirós: estudo crítico-biográfico por João Gaspar Simões. Rio de Janeiro: Aguilar, 1970.

- A correspondência de Fradique Mendes. Porto: Livraria Chadron, de Lel1o \& Irmão, Ltda., 1932.

- Cartas inéditas de Fradique Mendes. Porto: Livraria Chadron, de Lel10 \& Irmão, Ltda., 1929.

- Obras de Eça de Queirós: correspondência. Lisboa: Edição "Livros do Brasil", [s. d.].

- A cidade e as serras. Porto: Livraria Chadron, de Lē11o \& Irmão, Ltda., 1936.

- Contos. Introd. e notas de Augusto Pissara. Rio de Janeiro: Tecnoprint, 1970.

- Prosas bárbaras. Porto: Livraria Lello, 1935.

- Últimas páginas. 5. ed. Porto: Le110 \& Irmão, 1945.

- Lendas de Santos. In: Últimas páginas. 5. ed. Porto: Lel10 \& Irmão, 1945.

- 0 Francesismo. In: Últimas páginas. 5. ed. Porto: Lel1o \& Irmão, 1945. p. 397-425.

HUYSMANS, J.-K. À rebours. Paris: Fasquelle Éditeurs, 1970 (1884).

- Às avessas. Trad. José Paulo Paes. São Paulo: Companhia das Letras, 1987.

SCHOPENHAUER, Arthur. 0 mundo como vontade $e$ representação. Prefácio e tradução de Heraldo Barbuy. Introdução de Afrânio Coutinho. Rio de Janeiro: Tecnoprint, s. d. (Ediouro)

- O mundo como vontade e representação. Crítica da fillosofia kantiana; Parerga e paralipomena. Trad. Wolfgang Leo Maar e Maria Lúcia Mello e 0liveira Cacciola. São Paulo: Abril Cultural, 1980. (Os Pensadores)

- La riza. In: STEPANENKO, Pedro. Schopenhauer en sus páginas. México: Fondo de Cultura Económica, 1991. p. 77-83. 